\title{
"Green Web-II - Standards and Perspectives from the IUCN: Program and Policy Development in Environment Conservation Domain"
}

\author{
Manaslu Upadhyaya \\ Bunker Hill Community College, Boston, MA, USA
}

Correspondence: Manaslu Upadhyaya, Bunker Hill Community College, Boston, MA, USA Email mbhandar@syr.edu

Received: June 12, 2019 | Published: July 09, 2019

Copyright@ 2019 Upadhyaya. This is an open access article distributed under the terms of the Creative Commons Attribution License, which permits unrestricted use, distribution, and reproduction in any medium, provided the original author and source are credited.

\begin{abstract}
Book by Dr. Bhandari tells the real first-hand story of lifelong conversationalist/ social and environmental scientists along with the one of the oldest and largest conservation non-governmental organization- IUCN. The book cover reveals how an organization can make significant impact in conservation of nature and natural resources globally and in the developing world in particular. The role of international organization is depicted in a way that readers will travel along from IUCN HQ Switzerland to Bangkok and explore the environment conservation status and architecture of India, Nepal, Bangladesh, and Pakistan. Book is useful to all stakeholders who are interested to know the global environmental problems, what international organizations can do or cannot do. Book shows how theories can be applied to understand the role
\end{abstract}

of international organization with different economic, political, environmental and cultural stages. "Green Web-II provides a scholarly analysis of key drivers embraced by IUCN to understand the complexity of the scientific, cultural, social and political interactions that impact the sustainability of our natural world. Professor Bhandari lays out a blueprint for a sustainable future, where strategically communicated global values and standards, when coupled with cooperative and intentional personal efforts, can make the greatest difference on the future of our planet and all those who inhabit it".

Keywords: Medani Bhandari, IUCN, Nepal, India, Bangladesh, Pakistan, International Organization, Climate Change, Biodiversity, Knowledge, Social Theories, Popularity Index JEL Classification: Z13.

\section{Introduction}

I have never seen such an exceptionally written book, which starts from own experience of conservation of nature, connects with one of the largest and oldest organization's conservation domains and illustrates most of social theories. Book is wonderful to read, feel and apply in practical action for conservation of nature and natural resources.

\section{Discussion}

Being very honest, I am not sure how to begin to write a comment on a book, which combines theory and practice of environment conservation in a story form. Book reveals a deep pain and pleasure of an environment conservationist, who has spent and practiced his life pattern for nature conservation and educating people for conservation practically and theoretically. As a witness of his conservation journey, who has suffered more, given even more than he possesses. Let us look at the introduction [the first chapter], where, he briefly describes how he began to love nature and loving to nature as life pattern; however, in my opinion, introduction is short and insufficient. For example, in page number 4, he writes his resonant affection with IUCN and his willingness to make he himself co-founded organization Association for Protection of Environment and Culture (APEC-Nepal) to make a member of IUCN, he has to sell his land and even jewelry of his wife Prajita. In his own words "I formally applied for membership to IUCN in 1994 but was rejected due to opposition by some Indian and Nepali IUCN's NGO members. I appealed the case and won in
1995 but found that I could not pay the membership dues. I sold a piece of land that I owned but it was still not sufficient to pay two years (1994-1995) worth of dues. Fortunately, my wife Prajita, who is also co-founder of APEC, sold some of her jewelry (a gold ring and chain) which was sufficient to pay the full dues for two years that allowed for APEC to formally become a member of the IUCN (National NGO 1510)". As a general reader, I can understand, how much he was valuing IUCN. Is IUCN the organization who has 219 states government agencies members, $1100+$ NGOs members and $13000+$ experts in six commissions and $160+$ countries coverage as members (IUCN 2018), as listed in the IUCN website (https:// www.iucn.org/)? Does IUCN recognize, value, and appreciate Prof. Bhandari's dedications? In one of his papers, Prof. Bhandari states: "My intention of life is to pay back, give or contribute to the society in fullest whatever I have, earned, or experienced" 1-6. I guess, his intention is to give back the knowledge and expertise, but who needs them?

I tried to look at his list of interviewed respondents and found that 253 were the IUCN officials including the President to Director General (during 2008-2012) and about 500 IUCN commissions members of various countries. However, when I look at the book endorsers, yes, all were connected with IUCN once upon a time, I am repeating again, once upon a time. No one are current office bearer in the endorsement list (or who wrote comments about the book which is appeared in the printed version). While, writing this book review, I called and asked many questions about absence of IUCN current officials' endorsements or comments; whether he contacted IUCN officials or
Submit your Article | www. ologypress.com/submit-article OP Ology $f$ in $y$ ress
Citation: Upadhyaya M.“Green Web-II - Standards and Perspectives from the IUCN:Program and Policy Development in Environment Conservation Domain”. Adv Agr Environ Sci. (2019);2(2):93-95. DOI: I0.3088I/aaeoa.00026 
not? He responded; he did so many times, send many emails, even the River Publishers head contacted IUCN HQ, regional offices, national offices. But it seems that no one responded. It seems that IUCN have been missing their own asset. I suggest them to read this book, use it to make new policies and programs and circulate to all concern agencies for the same purpose. They are the ones who will be benefited more than any other readers.

I also askedanother question to myself and to Prof. Bhandari:“How many scholar books are available written a person who is not aIUCN official'? Surprisingly, I did not find any complete book and also Prof. Bhandari had no idea of anyone. The first complete book was written by Martin Holdgatein 1999 who was IUCN Director General 1988-1994 (IUCN 2010). Even in the introduction, Prof. Bhandari writes: "There are relatively few examples of research that examine the intervention of international organizations (IOs) in environmental conservation policy formation, or program planning and execution at the national and transnational levels. This research tries to fill this gap in knowledge by comparing four different South Asian nationstates with varying bureaucratic capabilities" (page 5).

In the book, Prof. Bhandari writes a number of times that IUCN is a knowledge producer, but in my opinion, yes, it might be so in the past, but at present IUCN does not seem to acknowledge people concern about IUCN and does not show any appreciation of conservation efforts made by other individuals or organizations. The entire book appreciates IUCNs efforts on conservation, its mechanism, history and even seeks more appreciation to IUCN, that does not seem appropriate. The book lacks the critical part of IUCN. As such, IUCN is no more as it was during 1990 or even during 2000. Its role is shrinking, value is diminishing, and it is natural and normal too. In theoretical term, it is organizational cycle and life and also its leadership.

Let me note the strong side of the book. As a formal IUCN CEC chair, Keith Wheeler notes: "This book describes a multi decade paradigm shift within the conservation community from species preservation to one focused on the role of sustainable development and the green economy. The Green Web-II provides a scholarly analysis of key drivers embraced by IUCN to understand the complexity of the scientific, cultural, social and political interactions that impact the sustainability of our natural world. Professor Bhandari lays out a blueprint for a sustainable future, where strategically communicated global values and standards, when coupled with cooperative and intentional personal efforts, can make the greatest difference on the future of our planet and all those who inhabit it" (page XX). Yes, as noted by Wheeler, the book reveals how much a person can do for nature and how she or he can contribute to the society. Similarly, Akamai University President Prof. Douglass Capogrossi states: "This outstanding book, Green Web-II: Standards and Perspectives from the IUCN - Program and Policy Development in Environment Conservation by Prof. Medani P. Bhandari, is the first known book of its kind, covering the role of IUCN, one of the grandest international membership-based environmental and conservation organizations. The book reveals Prof. Bhandari's lifelong love of nature, his motivation toward conservation and natural resources, and explains how IUCN became his dream organization. The book begins with a real-life story of the author's conservation activism for Nepal, India, Bangladesh, and Pakistan, where environmental issues are similar, but the approaches are somewhat different. This book serves as a resource for postgraduates and professors in understanding the theories and methods for research, concerning the pros and cons of biodiversity, forest conservation, parks management, and environmental policy.
General readers with interest in a sustainable world should find many things of interest toward establishing the green web for the future generation" (page XIX).I totally agree with Prof. Capogrossi, yes, book is outstanding, worths reading for all concerned stakeholders who deeply care about the nature and natural resources.

In the similar line Prof. Cecilia Green of Syracuse University, USA note that "Medani Bhandari has been a tireless warrior for green, prosperous, just peaceful, and biodiverse planet in which all living species co-habit in an environment of mindful sustainability. His book opens a window onto a little known and vastly under-used site of global institutional capacity for effective environmental governance at the national and international levels. This book will be of lasting encyclopedic usefulness for technicians and layperson alike. We should be extremely grateful to Dr. Bhandari for providing us with this much-needed tool" (page XX-XXI). Likewise, Odeh AlJayyousi, (formal regional director of IUCN), Professor of Arabian Gulf University states that "The book gives a new insight in the environmental conservation field, tries to convince readers to be a facilitator, convener, and bridge for knowledge and for transition to a sustainable future that celebrates diversity" (page XIII). Prof. Odeh provides a very valid evaluation of the book. The book is exceptional in every angle. Other two, Dr. Ambika Adhikari, USA (formal country director of IUCN) and Dr. Wendy Goldstein, Australia (formal head of education commission-IUCN) also highly appreciate the outstanding state of the book. I do not differ with these scholars' opinions, although, would like to add more.

As such, book covers theoretical frameworks, political economy of organizations, network theory, institutional theory, stakeholder theory, governance theory and elaborates each and every programs of IUCN with theoretical backing as well as provides a detail state of environment of India, Nepal, Bangladesh, and Pakistan, and links it how international organization can make positive impacts on conservation. The book covers: Motivation of Environment Conservation - How personal efforts make difference; - Role of International Environment Conservation Organizations; - Political Economy of Organizations, Network theory, Institutional theory, Stakeholder theory, Governance theory; - Governance performances and Competitiveness; - Popularity indices; - Knowledge creation and diffusion; and - Conservation commons"(back page of the book).

This is more than wonderful. However, Prof. Bhandari oversights the negative impact of international organization, and their imposed policies and the conflicts with the respected governments policy and program and practice at the local level. Book does briefly touch how IUCN is running business biodiversity programs, but oversight IUCN is endorsing the impacts of big organization on environment. I think, Prof. Bhandari loved IUCN too much, so he is not being able to spell out its negative side.

\section{Conclusion}

In sum, the book "Green Web-II - Standards and Perspectives from the IUCN: Program and Policy Development in Environment Conservation Domain - A Comparative Study of India, Nepal, Bangladesh, and Pakistan" is an asset for all concern stakeholders, who care for green planet, who care the marginalized society, and who wants to see the mother planet green. This book is a great sourcebook for sociologist, particularly organizational and environment domain and also serve a book for research method. The book can be resource particularly to the scholars, who need a guide of how theory can 
be utilize in scholarly research. Equally for the non-profit sector to see their role and for the policymakers, to examine the positive and negative role of international organizations. The book reveals a real thrive/passion and motivation of real conservationist and educator.

\section{Book is available at}

https://www.amazon.com/Green-Web-II-Perspectives-ConservationEnvironmental/dp/8770220123/ref=sr_1_1?ie=UTF8\&qid=1534358 $502 \&$ sr $=8-1 \&$ keywords $=$ medani + bhandari

https://books.google.com/books?hl=en\&lr=lang_en\&id= RNwDwAAQBAJ\&oi $=$ fnd $\& p g=P P 1 \& o t s=j \_J s b d i N Z L \& s i g=r-$ qyEsgBXLCz2SkEEcm_A_Ci8Io\#v=onepage\&q $\& \mathrm{f}=$ false

http://www.booksamillion.com/p/Green-Web-II-StandardsPerspectives/Medani-P-Bhandari/9788770220125\#reviews

\section{References}

1. Bhandari, Medani P. "Green Web-II - Standards and Perspectives from the IUCN: Program and Policy Development in Environment Conservation Domain - A Comparative Study of India, Nepal, Bangladesh and Pakistan”. River Publishers. (2018);13: 978-8770220125.
2. Bhandari, Medani P. "BashudaivaKutumbakkam"- The entire world is our home and all living beings are our relatives. Why we need to worry about climate change, with reference to pollution problems in the major cities of India, Nepal, Bangladesh, and Pakistan. Adv Agr Environ Sci. (2019);2(1): 8-35.

3. Holdgate Martin. The Green Web: A Union for World Conservation, Routledge, 1999.

4. IUCN (2018) Protected planet report 2018, tracking progress towards global targets for protected areas, UNEP-WCMCIUCN World Commission on Protected Areas (WCPA)National Geographic Society, US, Cambridge: UNEP-WCMC; Gland: IUCN; Washington, D.C.: NGS.

5. IUCN (2017), International Union for Conservation of Nature annual report 2017, Gland, Switzerland.

6. IUCN (2010), 50 Years of Working for Protected Areas, A brief history of IUCN World Commission on Protected Areas, Gland, Switzerland. 